\title{
EDITORIAL
}

\section{COVID-19 - THE LONG ROAD TO RECOVERY}

\author{
J.E. MORLEY
}

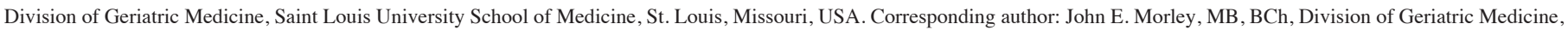

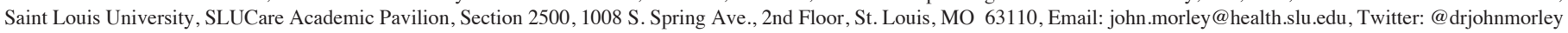

Key words: COVID-19, coronovirus, elderly.

"Seems like it's been a long journey in the past two months of recovery. I'm making progress and starting to walk independently with a cane. A little at a time but getting there." --Carol Todecheene

COVID-19 is a pandemic viral disease that has spread throughout the world in $2020(1,2)$. Nearly half of the persons with COVID-19 are asymptomatic. Older persons, persons with comorbidity and diabetes mellitus are particularly at risk of developing COVID-19. Severe cases of COVID-19 cause a viral pneumonia. In addition, COVID-19 can affect almost any organ in the body, as it enters cells through the angiotensin converting enzyme (ACE) 2 receptor (3). A subset of persons with COVID-19 appear to have a prolonged recovery period. This has been termed "long Covid" (4).

The concept of a viral disease leading to a post viral syndrome usually with chronic fatigue, is well recognized (5). In one study where patients were followed after having one of three viral diseases (Epstein Barr virus, Coxiella burnetti or Ross fever virus), $12 \%$ were found to have a specific syndrome for 6 or more months. Acute recurrences of the illness occurred in the first 3 months and chronic fluctuating symptoms included fatigue, cognitive disturbances, dysphoria, anxiety and pains in the muscles. This syndrome has also been termed myalgic encephalomyelitis (6).

After having had COVID-19, the Boston Red Sox pitcher, Eduardo Rodriguez was fatigued when throwing the ball and an MRI showed that he had myocarditis that will prevent him from pitching this year. There is now good evidence that the corona virus can invade myocardial cells and cause destruction of heart muscle (7). As is shown in Figure 1, myocarditis is not the only long-term side effect of COVID-19. These symptoms of "long Covid" include: fatigue, cough, dyspnea, loss of taste and smell, muscle weakness, muscle and joint pain, headache, confusion, conjunctivitis, chest pain, decreased mobility and falls $(8$, 9). It is important to recognize that persons who have severe pneumonia due to COVID-19 might take 6 months or longer to return their breathing to normal and that this is associated with decreased mobility. Elevated D-dimer levels are prognostic of poor lung function at 3 months (10).

Older persons who underwent lockdown with the COVID19 pandemic are likely to have decreased their exercise and developed sarcopenia. During this period health professionals and public health professionals failed to increase public awareness to reduce the development of sarcopenia and frailty (11-13). The marked increase in inflammatory cytokines in COVID-19 leads to an acceleration of muscle destruction and cachexia (14). The loss of muscle can be further aggravated by immobilization during hospitalization, which is even greater if the persons received artificial ventilation. All persons with COVID-19 should have bioavailable $25(\mathrm{OH})$ vitamin D measured (15) as during lockdown lack of sunlight can markedly reduce vitamin D in COVID-19 patients (16).

In addition to the muscle loss in "long Covid", the extended time at bedrest can lead to postural hypotension (17). Also, vasculitis during COVID-19 can lead to baroceptor damage 
resulting in autonomic dysregulation (18). Further, the increase in cytokines can damage the autonomic nervous system (19). Postural orthostatic tachycardia has also been observed in "long Covid." These factors can lead to an increase in falls, possibly associated with syncope. Persons who fall frequently or who are unsteady are likely to develop "fear of falling" (20).

Because of the increase in coagulopathy, persons with COVID-19 are at risk for having a stroke. These patients require neurorehabilitation to a similar degree of other persons with a cerebral vascular accident (21).

Delirium is not uncommon in acute COVID-19. Any precipitating causes should be avoided. Persons with delirium should not be physically restrained nor receive antipsychotics nor long acting benzodiazepines $(22,23)$. Delirium is associated with an increased mortality rate over the year following hospital admission (24). Persons with delirium show frontal hypometabolism and cerebellar hypermetabolism (25). Delirium should be screened for daily using either the confusion assessment method (CAM) or the 4-AT Rapid Clinical Test for Delirium (26-29).

Cognitive impairment is not unusual following COVID19. Besides the possibility of increased microthrombi in the brain, cerebral micro-structural changes have been identified in the hippocampus and multiple other brain areas (30). These changes were correlated with deterioration in cognition. Persons with cognitive impairment tend to describe a "brain fog" associated with fluctuations in behavior (31). Fatigue, while common, tends to fluctuate.

Acute COVID-19 is associated with renal tubular injury and focal sequential glomerulonephritis $(32,33)$. Kidney function needs to be carefully followed in persons who have had COVID-19 and care needs to be taken not to prescribe potentially nephrotoxic drugs.

\section{Rehabilitation}

In view of the multiple complications associated with "long Covid" it is essential that during recovery older persons are carefully followed by physicians and other health professionals. It is important to recognize that symptoms fluctuate and may go away for a few days and then return. There is a need for an integrated interprofessional care model to obtain the optimum recovery after COVID-19 (34).

The key to a good recovery is an exercise program adjusted to the ability of the patient to perform it. As has been shown by Izquierdo and his colleagues, these programs should be started in hospital and continued following hospital (3537). The ViviFrail exercise program is ideally adapted to doing this. Also, it is essential that while in the Intensive Care Unit, patients receive as much exercise as possible (38). These include respiratory exercises, passive joint motion, stretching, electrical stimulation of muscles, standing at bedside and walking where possible (39). On discharge the exercise program should include respiratory, resistance, aerobic and balance exercises as well as a focus on making sure the Activities of Daily Living can be adequately carried out. In view of the fatigue, exercises may need to be spread out during the day.

Speech therapy may need to help persons who have been ventilated to regain adequate speech patterns. In addition, they can work with occupational therapy to provide a variety of forms of cognitive stimulation therapy in those who have had a decline in their cognition $(40,41)$. Dietetics needs to work on creating taste enhancement of food in those who have lost their sense of taste and smell. Persons with sarcopenia or cachexia need supplementation with $10-15 \mathrm{~g} / \mathrm{kg} /$ day of leucine enriched essential amino acids $(42,43)$.

In view of the social isolation that occurs during the Covid epidemic it is important that programs are developed to provide socialization $(44,45)$. This can include telehealth programs such as the "Circle of Friends" as enhanced use of social media (46). Care should be taken to screen for dysphoria/depression and provide psychological therapy when it occurs (47).

It is suggested that at discharge from hospital and at 3 months discharge from hospital all COVID-19 patients are screened for frailty with the FRAIL test (48-51), sarcopenia with the SARC-F $(52-55)$, anorexia with the SNAQ $(56,57)$ and cognitive failure with the Rapid Cognitive Screen (RCS) (58). These tests are simply combined into the RAPID Geriatric Assessment $(59,60)$ and are available in an App form (61). Persons who screen positive and need to receive appropriate therapy which needs to be provided free to the individual.

"Long Covid" is an important condition which can respond to an interprofessional team approach. Its fluctuations can be frustrating both for the patient and the health care provider. An additional factor that needs to be taken into account is whether, in the long term, chronic subclinical chronic inflammation may lead to accelerated aging both in the periphery and as a neurodegenerative process $(62,63)$ ?

Disclosures: The author declares there are no conflicts.

\section{References}

1. Morley JE, Vellas B, Morley JE, et al. Editorial: COVID-19 and older adults. J Nutr Health Aging 2020;24:364-365.

2. Abbatecola AM, Antonelli-Incalzi R, Abbatecola AM, et al. Editorial: COVID-19 spiraling of frailty in older Italian patients. J Nutr Health Aging 2020;24:453-455.

3. Bahat G. Covid-19 and the Renin Angiotensin System: Implications for the older adults. J Nutr Health Aging 2020;24:699-704.

4. Greenhalgh T, Knight M, A'Court C, et al. Management of post-acute covid-19 in primary care. BMJ 2020;370:m3026. Doi: 10.1136/bmj.m3026.

5. Hickie I, Davenport T, Wakefield D, et al. Post-infective and chronic fatigue syndromes precipitated by viral and non-viral pathogens: Prospective cohort study. Brit Med J 2006;333:575 doi:10.1136/bmj38933.585764.AW.

6. Twisk F. Myalgic encephalomyelitis (ME) or what? An operational definition. Diagnostics (Basel) 2018;Sep 8;8:64. Doi:10.3390/diagnostics8030064.

7. Fox SE, Li G, Akmatbekov A, et al. Unexpected features of cardiac pathology in COVID-19 infection. Circulation 2020;142:1123-1125.

8. Paice JA, Dahlin C, Wholihan D, et al. Palliative care for people with COVID19-related symptoms. J Hosp Palliat Nurs 2020;Sep 8. Doi:10.1097/ NJH.0000000000000692. [Epub ahead of print].

9. Marshall M. The lasting misery of coronavirus long-haulers. Nature (News feature) Sept 14, 2020.

10. Zhao Y-M, Shang Y-M, Song W-B, et al. Follow-up study of the pulmonary function and related physiological characteristics of COVID-19 survivors three 


\section{THE JOURNAL OF NUTRITION, HEALTH \& AGING}

months after recovery. EClinicalMedicine 2020;Aug 25:100463. Doi: 10.1016/j eclinm.2020..100463. [Epub ahead of print].

11. Flatharta TO, Mulkrrin EC. Back to basics: Giant challenges to addressing Isaac's "Geriatric Giants" post COVID-19 crisis. J Nutr Health Aging 2020;24:705-707.

12. Woolford SJ, D'Angelo S, Curtis EM, et al. COVID-19 and associations with frailty and multimorbidity: A prospective analysis of UK Biobank participants. Aging Clin Exp Res 2020; July 23:1-9. Doi: 10.107/s40520-020-01653-6. [Epub ahead of print].

13. Ma Y, Hou L, Yang X, et al. The association between frailty and severe disease among COVID-19 patients aged over 60 years in China: A prospective cohort study. BMC Med 2020;18:274. Doi: 10.1186/s12916-020-01761-0.

14. Morley JE, Kalantar-Zadeh K, Anker SD. COVID-19: A major cause of cachexia and sarcopenia? J Cachexia Sarcopenia Muscle 2020;11:863-865.

15. Merchant RA, van Dam RM, Tan LWL Tan, et al. Vitamin B binding protein and vitamin D levels in multi-ethnic population. J Nutr Health Aging 2018;22:1060-1065.

16. Dos Santos RN, Maeda SS, Jardim JR, Lazaretti-Castro M. Reasons to avoid vitamin D deficiency during COVID-19 pandemic. Arch Endocrinol Metab 2020; Aug 28;S2359-39972020005006214.

17. Chen T, Hanna J, Walsh EE, et al. Syncope, near syncope, or nonmechanical falls as a presenting feature of COVID-19. Ann Emerg Med 2020;76:115-117.

18. Becker RC. Anticipating the long-term cardiovascular effects of COVID-19. J Thrombosis and Thrombolysis. 2020 Sep 3; doi: 10.1007/s11239-020-02266-6. [Epub ahead of print]

19. Shams A, Morley JE. Editorial: Autonomic neuropathy and cardiovascular disease in aging. J Nutr Health Aging 2018;22:1028-1033.

20. Merchant RA, Chen MZ, Wong BLL, et al. Relationship between fear of falling, fearrelated activity restriction, frailty, and sarcopenia. J Am Geriatr Soc 2020;Aug 17 doi 10.1111/jgs.16719. [Epub ahead of print].

21. Siepmann T, Sedghi A, Simon E, et al. Increased risk of acute stroke among patien with severe COVID-19: A multicenter study and meta-analysis. Eur J Neurol 2020; Sep 12 doi; 10..1111/ene.14535. [Epub ahead of print].

22. Flaherty JH, Morley JE. Delirium in the nursing home. J Am Med Dir Assoc 2013; 14:632-634

23. Deng L-X, Cao L, Zhang L-N, et al. Non-pharmacological interventions to reduce the incidence and duration of delirium in critically ill patients: A systematic review and network metaanalysis. J Crit Care 2020;60:241-248

24. Losee S, Hanson H. COVID-19 delirium with psychosis: A case report. SD Med 2020;73:346-349.

25. Delorme C, Paccoud O, Kas A, et al; CoCo-Neurosciences Study Group and COVID SMIT PSL study group. COVID-19-related encephalopathy: A case series with brain FDG-PET/CT findings. Eur J Neurol 2020;Aug 15. Doi: 10.1111/ene.14478. [Epub ahead of print].

26. Emmerton D, Abdelhafiz A. Delirium in older people with COVID-19: Clinical scenario and literature review. SN Compr Clin Med 2020 Aug 29:1-8 [Epub ahead of print]

27. Wei LA, Fearing MA, Sternberg EJ, Inouye SK. The confusion assessment method A systematic review of current usage. J Am Geriatr Soc 2008;36:823-830.

28. Saller T, MacLullich AMJ, Perneczky R. The 4AT - an instrument for delirium detection for older patients in the post-anaesthesia care unit. Anaesthesia 2020;75(3):410. Doi: 10.1111/anae.14937.

29. MacLullich AMJ, Shenkin SD, Goodcare S, et al. The 4 'A's test for detecting delirium in acute medical patients: A diagnostic accuracy study. Health Techno Assess 2019;23:1-194.

30. Lu Y, Li X, Geng D, et al. Cerebral micro-structural changes in COVID-19 patients an MRI-based 3-month follow-up study. EClinicalMedicine 2020; Aug 3; 25:100484 Doi: 10.1016/j.eclinm.2020.100484. [Epub ahead of print]

31. Yelin D, Wirtheim E, Vetter P, et al. Long-term consequences of COVID-19: Research needs. Lancet Infect Dis 2020. Doi: 10.1016/S1473.3099(20)30701.5 [In press].

32. Su H, Yang M, Wan C, et al. Renal histopathological analysis of 26 postmortem findings of patients with COVID-19 in China. Kidney Int 98:219-227.

33. Peleg Y, Kudose S, D'Agati V, et al. Acute kidney injury due to collapsing glomerulopathy following COVID-19 infection. Kidney Int Rep 5:940-945.

34. O'Brien H, Tracey MJ, Ottewill C, et al. An integrated multidisciplinary model of COVID-19 recovery care. Ir J Med Sci 2020; doi:10.1007/s11845-020-02354-9. [Epub ahead of print]

35. Valenzuela PL, Morales JS, Castillo-Garcia A, et al. Effects of exercise interventions on the functional status of acutely hospitalized older adults: A systematic review and meta-analysis. Ageing Res Rev 2020;Aug.61:101076. Doi: 10.1016/j. arr.2020.101076. [Epub ahead of print].

36. De Asteasu MLS, Martinez-Velilla N, Zambom-Ferraresi F, et al. Physical exercise improves function in acutely hospitalized older patients: Secondary analysis of a randomized clinical trial. J Am Med Dir Assoc 2019;20:866-873.

37. Izquierdo M, Morley JE, Lucia A. Exercise in people over 85. BMJ 2020;368:m402. Doi: $10.1136 /$ bmj.m402.

38. Doirin KA, Hoffmann TC, Beller EM. Early intervention (mobilization or active exercise) for critically ill adults in the intensive care unit. Cochrane Database Sys Rev 2018;Mar 27; 3(3):CD010754
39. Zhu Y, Wang Z, Zhou Y, et al. Summary of respiratory rehabilitation and physical therapy guidelines for patients with COVID-19 based on recommendations of World Confederation for Physical Therapy and National Association of Physical Therapy. J Phys Ther Sci 2020;32:545-549.

40. Scherrer JF, Morley JE. Lowering dementia risk and slowing progression of disease: The role of cognitive reserve and cognitive training. Br J Psychiatry 2020; Jul 1;1-2. Doi: 10.1192/bjp.2020.119 [Epub ahead of print].

41. Stewart DB, Berg-Weger M, Tebb S, et al. Making a difference: A study of cognitive stimulation therapy for persons with dementia. J Gerontol Soc Work 2017;60:300312

42. Bauer JM, Mikusova L, Verlaan S, et al. Safety and tolerability of 6-month supplementation with a vitamin $\mathrm{D}$, calcium and leucine-enriched whey protein medical nutrition drink in sarcopenic older adults. Aging Clin Exp Res 2020;32:15011514.

43. Bauer J, Biolo G, Cederholm, et al. Evidence-based recommendations for optima dietary protein intake in older people: A position paper from the PROT-AGE study group. J Am Med Dir Assoc 2013;14:542-559.

44. Berg-Weger M, Morley JE. Editorial: Loneliness and social isolation in older adult during the COVIVD-19 pandemic: Implications for gerontological social work. J Nutr Health Aging 2020;24:456-458.

45. Berg-Weger M, Morley J. Editorial: Loneliness in old age: An unaddressed health problem. J Nutr Health Aging 2020;24:243-245.

46. Sirinavasin SR, Srinivasan SR. Editorial: Tele-ICU in the age of COVID-19: Built for this challenge. J Nutr Health Aging 2020;24:536-537.

47. Chan E-Y, Lim Z-X, Ding YY, Chan YH, Lim WS. Development of a brief caregiver-centric screening tool to identify risk of depression among caregivers of hospitalized older adults. J Nutr Health Aging 2019;23:578-585.

48. Woo J, Yang X, Tin Lui L, et al Utility of the FRAIL questionnaire in detecting heart failure with preserved ejection fraction. J Nutr Health Aging 2019;23:373-377.

49. Charbek E, Espiritu JR, Nayak R, Morley JE. Editorial: Frailty, comorbidity, and COPD. J Nutr Health Aging 2018;22:876-879.

50. Morley JE. Frailty screening comes of age. J Nutr Health Aging 2014;18:453-454.

51. Dent E, Morley JE, Cruz-Jentoft AJ, et al. Physical frailty: ICFSR International Clinical Practice guidelines for identification and management. J Nutr Health Aging 2019;23:771-787.

52. Bahat G, Yilmaz O, Kilic C, et al. Performance of SARC-F in regard to sarcopenia definitions, muscle mass and functional measures. J Nutr Health Aging 2018;22:898 903.

53. Sanchez-Rodriguez D, Marco E, Davalos-Yerovi V, et al. Translation and validation of the Spanish version of the SARC-F questionnaire to assess sarcopenia in older people. J Nutr Health Aging 2019;23:518-524

54. Kurita N, Wakita T, Kamitani T, et al. SARC-F validation and SARC-F + EBM derivation in musculoskeletal disease: The SPSS-OK Study. J Nutr Health Aging 2019;23:732-738.

55. Morley JE. Frailty and sarcopenia: The new geriatric giants. Rev Invest Clin 2016;68:59-67.

56. Mohammadi MR, Akhondzadeh S, Keshavarz SA, Mostafavi SA. The characteristics, reliability and validity of the Persian version of simplified nutritional appetite questionnaire (SNAQ). J Nutr Health Aging 2019;23:837-842.

57. Wang T, Shen J. Usefulness of Simplified Nutritional Appetite Questionnaire (SNAQ) in Appetite Assessment in elderly patients with liver cirrhosis. J Nutr Health Aging 2018;22:911-915.

58. Malmstrom TK, Voss VB, Cruz-Oliver DM, et al. The Rapid Cognitive Screen (RCS): A point-of-care screening for dementia and mild cognitive impairment. J Nutr Health Aging 2015;19:741-744.

59. Tuna F, Usundag A, Basak Can H, Tuna H. Rapid geriatric assessment, physical activity, and sleep quality in adults aged more than 65 years: A preliminary study. J Nutr Health Aging 2019;23:617-622.

60. Sanford AM, Morley JE, Berg-Weger M, et al. High prevalence of geriatric syndromes in older adults. PLoS One 2020;15:e0233857.

61. Merchant RA, Yeong Hui RJ, Kwek SC, et al. Rapid geriatric assessment using mobile app in primary care: Prevalence of geriatric syndromes and review of its feasibility. Front Med (Lausanne) 2020;7:261. eCollection 2020. Doi: 10.3389/ fmed.2020.00261.

62. Bektas A, Schurman SH, Franceschi C, Ferrucci. A public health perspective of aging: Do hyper-inflammatory syndromes such as COVID-19, SARS, ARDS, cytokine storm syndrome, and post-ICU syndrome accelerate short- and long-term inflammaging? Immun Ageing 2020; Sug 24;17:23 doi: 10.1186/s12979-020-001968. eCollection 2020.

63. Bossu P, Toppi E, Sterbini V, Spalletta G. Implication of aging related chronic neuroinflammation on COVID-19 pandemic. J Pers Med 2020;Aug 26;10(3):E102 Doi: $10.3390 / \mathrm{jpm} 10030102$ 